\title{
Morbidity in extreme low birth weight newborns hospitalized in a high risk public maternity
}

Derijulie Siqueira Sousa 1

Airton Salviano Sousa Júnior 2

Arielly Duarte Rabelo Santos 3

Enaldo Vieira Melo 4

Sônia Oliveira Lima 5

Marcos Antônio Almeida-Santos 6

Francisco Prado Reis 7

1,5,6,7 Programa de Pós-graduação em Saúde e Ambiente. Universidade Tiradentes. Aracaju, Av. Murilo Dantas Farolandia. SE, Brasil. CEP: 49.032-490. E-mail: Derijulie@hotmail.com

2,3 Universidade de Tiradentes. Aracaju, SE, Brasil.

4 Universidade Federal de Sergipe. Aracaju, SE, Brasil.

\begin{abstract}
Objectives: to determine the prevalence of the most common morbidities in extremely low birth weight (ELBW) infants hospitalized in a newborn intensive care unit (NICU) and to evaluate the influence of these morbidities through the length of in-hospital stay.

Methods: observational, longitudinal, prospective and analytical study in a high risk reference maternity NICU from Sergipe, realized with 158 ELBW infants admitted between March 2014 and April 2015. The analysis of the hospitalization time was realized through the Kaplan-Meier method.

Results: the average weight of premature was $785,2 \mathrm{~g} \pm 138,2 \mathrm{~g}$. The gestational age vary from 22 to 35 weeks and the average was 26,8 weeks. Of those admitted at NICU, sixty three $(39,9 \%)$ were discharged and $95(60,1 \%)$ died. The time of hospitalization was influenced for morbidities as: patent ductus arteriosus (PDA), intraventricular hemorrhage and sepsis. Acute respiratory distress syndrome was the most common complication $(157-99,4 \%)$. The incidence of persistent arterial duct, intraventricular hemorrhage, sepsis, hypothermia, hypoglycemia and retinopathy of prematurity was $39,2 \%, 17,1 \%, 32,3 \%, 50,3 \%, 52,3 \%$ e 16,6\% respectively.

Conclusions: the morbidities from respiratory tract, cardiac, neurological and infectious were the most prevalent, whilst PDA, intraventricular hemorrhage and sepsis were the morbidities that significantly influenced the time of hospitalization.
\end{abstract}

Key words Morbidity, Infant, premature, Intensive care units, neonatal (NICU) 


\section{Introduction}

World Health Organization (WHO) (2012) defined premature birth as the one which occurs after the $20^{\text {th }}$ week and before $37^{\text {th }}$ week of pregnancy. Prematurity can be classified in 3 categories: mild, when occurs between 32 and 36 weeks, moderate ( 28 and 31 weeks) and severe (under 28 weeks). ${ }^{1}$

The lower the gestational age (GA), the higher the mortality and morbidity taxes are, and consequently higher the chance for the child to present sequels that can show up as it develops. ${ }^{2}$ The organs and vital system immaturity make the newborns (NB) vulnerable and more susceptible to the development of complications in their health. ${ }^{3}$ In the year of 2010, the complications which came from prematurity were responsible for $14 \%$ of deaths of children under five years old. 4

The Ministry of Health (MH), under a newborn healthcare guideline, had appointed the main morbidities which occurred in premature newborns (NBs). The MS work had, as objectives, to enhance the access to standard information to healthcare professionals; the quality of healthcare provided both to the pregnant women and NB; to reduce mortality and morbidity in the neonatal period. 5

The edges of fetal and neonatal viability have been enlarged, and increasingly, newborns with extreme low weight (birth weight under $1000 \mathrm{~g}$ ) have been surviving. 6 This epidemiological configuration on the newborn's heath, mainly premature and extreme low weight NBs has been increasingly making necessary the use of technology in the newborn healthcare, not only to raise the survival rate, but also to provide care based in their specific needs. 5

This progress regarding study and technology concerning neonatology has increased the survival of much more immature premature, and specially decreasing the mortality rates in the neonatal period. This has a cost, observing the emergence of a higher amount of complications and aggravations due to the prematurity itself, as well as the extended hospitalization time of these NBs. ${ }^{7}$

These advances in the perinatal assistance, including new technology focused on surfactant reposition therapy, mechanic ventilation (MV) and standardized service focused on premature needs in birth rooms resulted in a significant rise on the survival rate for extreme low weight newborns. ${ }^{8}$ Potentially, these measures represent a relevant contribution, observing the high hospitalar cost in the service to that individuals, whose internments also implies in early weaning, separation from famil- iars and emotional disturbs and overload of healthcare system. ${ }^{9}$

Studies conducted in developed countries have demonstrated that the enhancement in neonatal assistance have positively influenced the extreme low weight NBs' health. In the United States, in the early 90 's, an improvement of $49 \%$ to $68 \%$ was noticed on the survival of premature children. 10 In Finland, from years 199-2000, a research showed that the survival rate was of $65 \%$ in NBs with extreme low weight. ${ }^{11}$ Recently, a multicentric study executed in 26 Maternities in China, the authors related a global rate of survival in NBs with extreme low weight of $50.0 \%{ }^{8}$ However, studies concerning the survival of NBs with extreme low weight still scarce, especially in developing countries.

The strands amongst the causes of prematurity and its main complications need of secure and effective interventions. 12 The authors yet highlight the main pathologies which can be avoided by an appropriated care for the NB, that is, respiratory, cardiovascular, endocrine and metabolic disorders, as well as infections. All of these considered as main causes.

This study aims to determine the prevalence of the most common morbidities in newborns with extreme low weight, who are admitted in an intensive care unit, and to evaluate the influence of these morbidities on the length of hospital stay.

\section{Methods}

Observational, longitudinal study,prospective and analytic, develop at a Neonatal Intensive Care Unit (NICU) in a public maternity, reference at high risk, in Sergipe State, with care by the Health Unic System, covering 75 municipalities from the state and also some from neighboring states.

The population was constituted by 154 newborns in extreme low birth weight (NBELB). Were included all newborns with birth weight equal/greater than $500 \mathrm{~g}$ than $500 \mathrm{~g}$ and less than $1000 \mathrm{~g}$, at the moment of their admission in NICU in a period from March 2014 to April 2015.

A questionnaire was elaborated by the researchers, with previously established items, which was divided in three sections: I - approach to maternal and gestational factors; II - occurrences during birth; III - neonatal factors, related to the main morbidities presented by the NBs during the hospital stay. The questionnaire was fulfilled with collected data from the newborn medical records.

As outcome variables, the following factors were related:

a) Gestational: type of gestation, maternal age, 
presence of infection during pregnancy, complications during pregnancy, adherence to prenatal examination.

b) Peripartum: type of parturition, birth weight, necessity of resuscitation maneuvers during the birth.

c) Neonatal: morbidities presented by the newborns during the hospital admission.

The numerical variables were described as average and standard deviation. For the categorical variables, simple frequencies and percentage with confidence interval of $95 \%$ for the outcome variable were used.

The analysis from hospital admission length and associated factors was executed by the survival analysis technique through Kaplan-meier method and the log-rank test.

Graphics which compare the distribution of length of hospital stay with or without the presence of morbidities.

The SPSS (Statistical Package for Social Sciences) program, 19.0 test-version, was used to statistic calculations.

The project was approved by Ethics and Research Committee (CEP) from Tiradentes University (UNIT), in February 2014, CAAE 20210113.30000.5371, according to recommendations from 466/2012/CSN/MS/CONEP resolution.

\section{Results}

In the period of research, from March 2014 to April 2015, 158 NBELB were admitted in the maternity's NICU, being: $72(45.6 \%)$ male and $86(54.4 \%)$ female. NBs presented an average weight of $785.2 \mathrm{~g}$ $\pm 138.2 \mathrm{~g}$, with a minimum of $500 \mathrm{~g}$ and a maximum of $996 \mathrm{~g}$. The average of pregnancy age (PA) was of 26.8 weeks, and varied between 22 and 35 weeks. The vaginal delivery prevailed at births $116(76.4 \%)$ when related to 42 Cesarean delivery births $(26.6 \%)$.

The registry of Apgar value, in the first and fifth minute of life, was used to evaluate the condition of birth. In the first minute a median value equal to 5 , with interquartile interval of 3-7 was registered. In the fifth minute, the median was 8 , with interquartile interval 7-9. These values indicate the occurrence, of moderated to severe asphyxia in these $\mathrm{Nbs}$, in the first minutes of life. Among the Nbs, 122 (72.2\%) needed routine maneuvers in birth room, such as: aspiration, oxygen supply, tracheal intubation and the first dose of surfactant, in some cases.

Relating to the outcome variables, (discharge, death, and hospital stay time): it was possible to identify that the frequency of deaths was of $60.1 \%$ with IC 95(1.9-67.7) and 39.9\% of the NBs were discharged from NICU. The hospital stay time presented a median of 11 days, that is, half from the admitted NBELBs remained hospitalized until the eleventh day of life. In the other hand, $25 \%$ of the NBELBs remained hospitalized until the second day and the left $25 \%$, until a period greater than 50 days.

The mothers of NBELBs were young, 38\% under 19 years old, and the type of gestation which prevailed was single $(81 \%)$, followed by twin gestation (16.5\%) and trigeminal gestation $(2.5 \%)$. There wasn't any registry of assisted reproduction gestation. Regarding prenatal assistance, $86.1 \%$ had less than six appointments, $60.5 \%$ presented urinary infection during the gestation and $51.9 \%$ had broken bag during labor, with presence of clear amniotic fluid in $98.1 \%$ of cases (Table 1).

Table 2 shows the main types of morbidities presented by the Nbs. It can be noted that the in the respiratory system, $99.4 \%$ of the NBELBs presented Hyaline membrane; in the circulatory system, $39.4 \%$ had patent ductus arteriosus; among neural morbidities, intracranial hemorrhage prevailed with a frequency of $17.1 \%$; and sepsis was highlighted in infectious diseases, with $32.3 \%$. From evaluated metabolic diseases, hypoglycemia, hypothermia and jaundice had a frequency of $52.9 \%$ to $47.8 \%$, respectively. A registry of congenital syphilis has still been found in $7.6 \%$ of the NBs, and $16 \%$ presented retinopathy of prematurity (ROP).

Among the morbidities which contributed to the length of hospital admission, the following stood out: pulmonary hypertension, PDA, intraventricular hemorrhage and sepsis.

The NBs with PDA presented a distribution of length of hospital stay significantly higher $(\mathrm{p}=0.04)$, when compared to NBs without this morbidity. Thus, according to Figure 1 it is possible to observe that in the $30^{\text {th }}$ day of life, $100 \%$ of NBs remained hospitalized, whilst approximately $18 \%$ of NBs died or would die thereafter.

There was a significant difference $(p=0.035)$ in the distribution of length of hospital stay among the patients which presented sepsis or not. According to Figure 2 illustration, it is possible to observe that until the $40^{\text {th }}$ day of admission $90 \%$ of NBELBs who had sepsis diagnosis remained hospitalized, whilst $80 \%$ of those without sepsis had been discharged from NICU or had died.

The NBELBs which presented intraventricular hemorrhage have also presented a distribution of hospital stay significantly higher $(p=0.014)$, when related to NBELBs without this diagnosis. As shown in Figure 3, it is possible to observe that $100 \%$ of 
NBELBs with intraventricular hemorrhage had been hospitalized until the $40^{\text {th }}$ day of life, whilst $20 \%$ of patient who didn't present this diagnosis had death as outcome.

\section{Discussion}

All of the 158 NBELBs from the present study, hospitalized in NICU, received treatment, specific and necessary interventions for the maintenance and improvement of their clinical condition, having $39.9 \%$ of them been discharged. In a study conducted by Lin et al., 8 with 258 NBELBs, during the period of a year, the survival rate was of $50 \%$.

Despite the significant advance of the neonatology, the prevalence of premature births has been alarming, both in Brazil and abroad, not only about the demands of a better quality in assistance, but also in the regards of the increase of hospital costs. ${ }^{9,13}$ According to data from System of Information about Live Births (SINASC), the number of NBELBs births, in state of Sergipe, between 2010 and 2013, had reached 596 cases, with a higher amount of cases (164) in the year of 2012.14

Table 1

Clinical and biological characteristics of the pregnant women and newborns in extreme low weight at high risk, admitted in NICU in a public maternity in Aracaju SE, 2014/2015.

\begin{tabular}{|c|c|c|}
\hline Gestational factors & $\mathbf{N}$ & $\%$ \\
\hline \multicolumn{3}{|l|}{ Maternal age (years) } \\
\hline$<19$ & 60 & 38.0 \\
\hline 20 to 29 & 58 & 36.7 \\
\hline 30 to 39 & 38 & 24.1 \\
\hline 40 or over & 2 & 1.3 \\
\hline \multicolumn{3}{|l|}{ Type of gestation } \\
\hline Single & 128 & 81.0 \\
\hline Twin & 26 & 16.5 \\
\hline Trigeminal & 4 & 2.5 \\
\hline \multicolumn{3}{|l|}{ Prenatal care } \\
\hline Less than six appointments & 136 & 86.1 \\
\hline Six appointments & 13 & 8.2 \\
\hline Seven appointments or more & 9 & 5.7 \\
\hline \multicolumn{3}{|l|}{ Urinary infection during gestation } \\
\hline Yes & 96 & 60.8 \\
\hline No & 62 & 39.2 \\
\hline \multicolumn{3}{|l|}{ Broken bag } \\
\hline Yes & 82 & 51.9 \\
\hline No & 76 & 48.1 \\
\hline \multicolumn{3}{|l|}{ Aspect of amniotic fluid } \\
\hline Clear & 155 & 98.1 \\
\hline Meconium-stained & 3 & 1.9 \\
\hline
\end{tabular}




\section{Table 2}

Types of morbidities in newborns in extreme low weight at high risk, admitted in NICU from public maternity inAracaju SE, 2014/2015.

\begin{tabular}{|c|c|c|c|}
\hline Morbidities & $\mathbf{N}$ & $\%$ & $\mathrm{Cl} 195 \%$ \\
\hline \multicolumn{4}{|l|}{ Respiratory } \\
\hline Hyaline membrane & 157 & 99.4 & $98.1-100.0$ \\
\hline Pulmonary hypertension & 24 & 15.2 & $10.1-20.9$ \\
\hline Meconial fluid aspiration & 2 & 1.3 & $0.0-3.2$ \\
\hline Apnea & 34 & 21.5 & $15.8-27.2$ \\
\hline Pulmonary hemorrhage & 44 & 27.8 & 20.9- 34.8 \\
\hline Cronic pulmonary disease & 2 & 1.3 & $0.0-3.2$ \\
\hline \multicolumn{4}{|l|}{ Cardiac } \\
\hline Congenital cardiopathy & 1 & 6.0 & $0.0-1.9$ \\
\hline Patent ductus arteriosus (PDA) & 62 & 39.2 & $31.6-46.8$ \\
\hline Shock & 29 & 18.4 & $12.7-24.7$ \\
\hline \multicolumn{4}{|l|}{ Neurological } \\
\hline CNS Hemorrhage & 27 & 17.1 & 11.4- 23.4 \\
\hline Seizures & 19 & 12.0 & $7.0-17.7$ \\
\hline \multicolumn{4}{|l|}{ Infection } \\
\hline Infectious diseases & 30 & 19.0 & $12.7-25.3$ \\
\hline Pneumonia & 43 & 27.2 & 20.9- 33.5 \\
\hline Bacterial meningitis & 4 & 2.5 & $0.6-5.7$ \\
\hline Sepsis & 51 & 32.3 & 25.3- 39.9 \\
\hline Congenital syphilis & 12 & 7.6 & $3.8-12.0$ \\
\hline \multicolumn{4}{|l|}{ Metabolic } \\
\hline Hypoglycemy & 83 & 52.3 & $45.2-60.5$ \\
\hline Hypothermia & 79 & 50,3 & $42.0-58.0$ \\
\hline Jaundice & 75 & 47.8 & $39.5-56.1$ \\
\hline \multicolumn{4}{|l|}{ Ophthalmologic } \\
\hline Retinopathy & 26 & 16.6 & $11.5-22.3$ \\
\hline \multicolumn{4}{|l|}{ Gastrointestinal } \\
\hline Necrotizing enterocolithis & 12 & 7.6 & $3.8-12.0$ \\
\hline
\end{tabular}

CNS= central nervous system 
Figure 1

Proportion of NBELBs hospitalized depending on the time related to cardiac morbidity Patent ductus arteriosus admitted in high risk public maternity NICU in Aracaju, Se, 1014/2015.

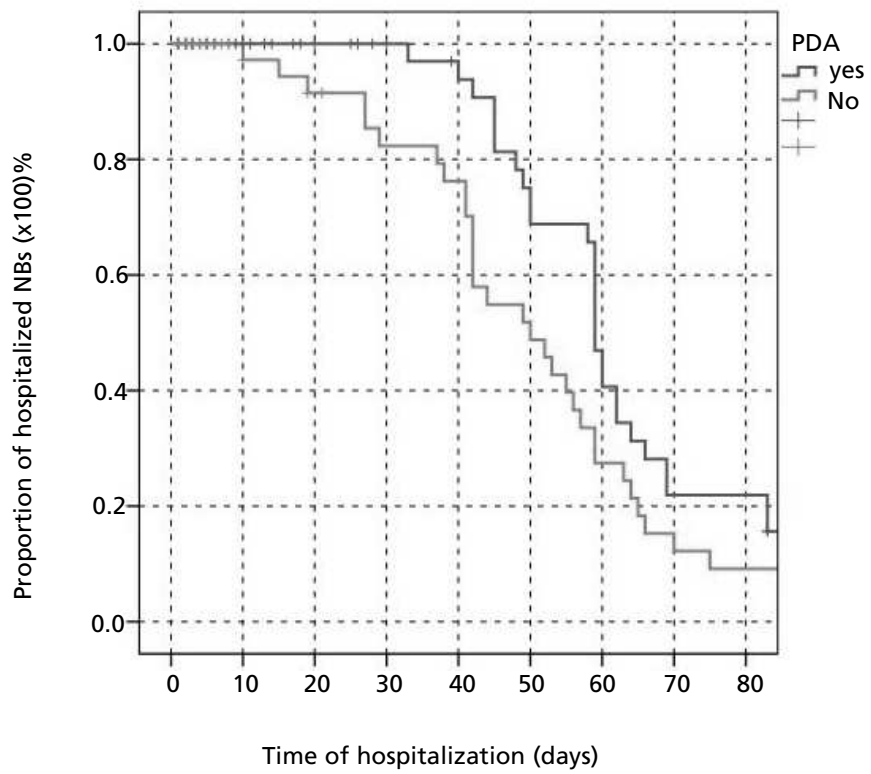

Log-rank test; $p=0.04$

\section{Figure 2}

Proportion of NBELBs hospitalized depending on the time related to sepsis admitted in high risk public maternity NICU in Aracaju, SE, 2014/2015.

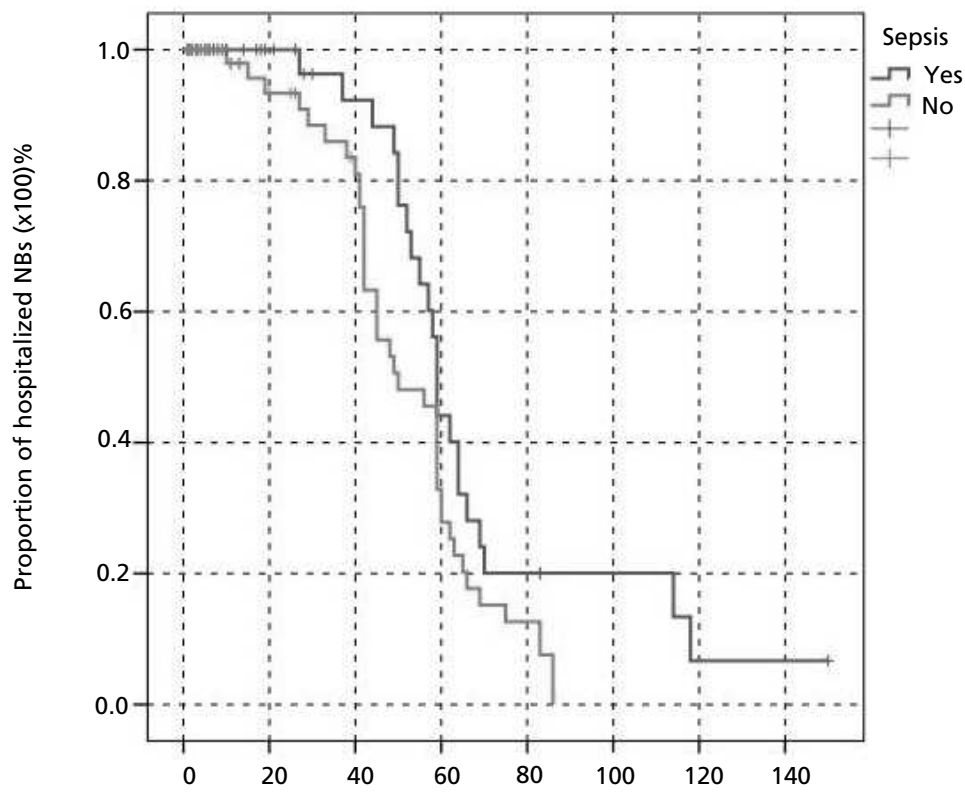

Time of hospitalization (days)

Log-rank test; $p=0.035$. 
Figure 3

Proportion of NBELBS hospitalized depending on the time related to neurological morbidity intraventricular hemorrhage admitted in high risk public maternity NICU in Aracaju, SE, 2014/2015.

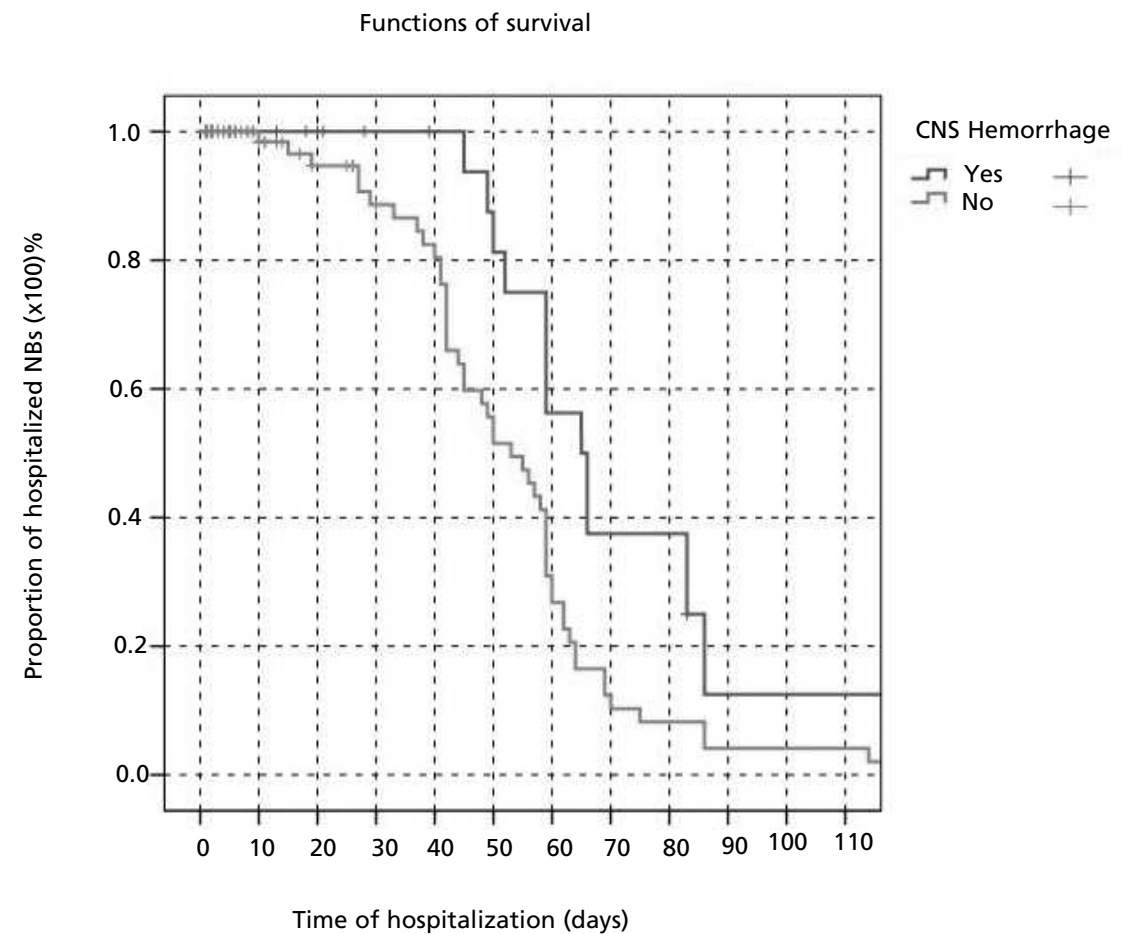

Log-rank test; $p=0.014$

The increase of premature births has been related to several factors, such as: new fertilizing methods, and the consequent increase of twin gestations; the rising number of gestations in the group of women over 35 years of age; the increasing of medical indication for cesarean delivery, due to the higher use of technology in the pregnancy monitoring. ${ }^{15}$ In the present study, the majority of women was under 19 years of age, none of them used any fertilization method, having the majority had single gestation, as well as the number of vaginal deliveries.

A finding which made it difficult to recognize the cause of premature births was the low adherence to prenatal control, observing that $86.1 \%$ of the women had not attended a number of appointments equal or over six, as preconized by World Health Organization (WHO), which yet highlighted the early adherence to prenatal examination as being extremely important for a quality assistance. 4 The prenatal control is indispensable for the early detection of inter-occurrences, as well as the implementation of disease prevention action. 16 It is the moment to identify diseases which can affect both baby and mother during the gestation and lead to prematurity.

The correct Apgar index evaluation is indispensable and most of times decisive for a safe and effective care in the NBs initial minutes of life. The Apgar index from $1^{\text {st }}$ to $5^{\text {th }}$ minuteis an indicator of the state of extra-uterine adaptation, as well as the NB oxygenation in the ante and intrapartum period, and can be used as a fetal vitality evaluator, as well as initial prognostic for the newborn. ${ }^{17}$ In the study, it was possible to observe that the NBELBs were classified in the first minute as having sever asphyxia, and that after resuscitation maneuvers applied in $77,2 \%$ of the NBs, an improvement had occurred.

The presence of breathing problems has high level of occurrence, which was frequently attributed to immaturity in NBELBs' organism. According to Tamez and Silva, 18 anatomic and functional 
maturation of the lungs requires, at least, 35 weeks of gestation. Functional development of fetal lung and surfactant production are necessary for the normal respiratory function. The surfactant synthesis starts from $23^{\text {th }}$ to $24^{\text {th }}$ week of gestation. The findings of the present study confirmed a high occurrence of respiratory morbidities, being highlighted hyaline membrane (99.4\%) and pulmonary hemorrhage $(27.8 \%)$. Lin et al. ${ }^{8}$ also related the presence of hyaline membrane as the main occurring morbidity in NBELBs.

Still in relation to complications on respiratory system, in this study, apnea occurred in $21.5 \%$ of cases. According to Rodrigues e Magalhães, ${ }^{1}$ this morbidity occurs, approximately, in $70 \%$ of the NBs with less than 34 weeks of gestational age, being more frequent in the less mature ones $(25 \%$ of occurring in the NBs in birth weight under $2500 \mathrm{~g}$ and $84 \%$ in the ones with less than $1000 \mathrm{~g}$ ).

The patent ductus arteriosus (PDA) has been described as one of the morbidities with most common occurrence among premature NBs. Its occurrence has been varying from $53 \%$ to gestational age (GA) premature babies under 34 weeks, and can reach $65 \%$ in premature infants with GA lower than 26 weeks. ${ }^{19}$ For Stoller et al.,20 PDA in premature infants may be associated to pulmonary hemorrhage. In the present study, $39.2 \%$ of the NBELBs presented PDA, and 24 (15.2\%) had pulmonary hypertension. This kind of morbidity had influence on NBELBs the time of hospitalization.

Peri-intraventricular hemorrhage (PIVH) is known as the type of intraventricular hemorrhage characteristic to the preterm newborn (PTNB) and has been directly related to the level of prematurity. Rodrigues and Magalhães ${ }^{1}$ related that despite the current improvement on the care of these newborns and the higher survival rate of extreme preterm infants, this type of morbidity remains as the greatest problem at the Neonatal Intensive Care Units. In the present study, it was observed that $17.1 \%$ of the NBELBs presented this type of morbidity, of which

\section{References}

1. Rodrigues FPM, Magalhães M. Normas e Condutas em Neonatologia. 2 ed. São Paulo: Atheneu; 2011.

2. Rolnik DL, Bittar RE, Carvalho MHB de, Zugaib M, Francisco RPV. Predição do parto prematuro : avaliação sequencial do colo uterino e do teste para proteína-1 fosforilada ligada ao fator de crescimento insulina-símile. Rev Bras Ginecol Obs. 2013; 35 (9): 394-400.

3. Cucolo DF, Faria JIL, Cesarino CB. Avaliação emancipatória de um programa educativo do serviço de controle
$90 \%$ had a length hospital stay of approximately 40 days.

Regarding the time of hospitalization, Lanzillotti et al. ${ }^{21}$ related as being lengthy, and this way, it is passible of a higher exposition of the NBs to potential risk of infections. In the study, it was possible to observe that sepsis was registered as the main infectious disease and it had reached $32.2 \%$ of the infants and influenced the length of hospital stay, once $100 \%$ of the NBELBs which presented this diagnosis got hospitalized for at least 40 days.

One of the NBs complications is the ineffective thermo-regulation after birth, when the heat produced by the NB is lost in consequence of the evaporation and the external environment temperature. 22 In the present study, $50.3 \%$ of the NBELBs had episodes and complications related to hypothermia. $52.9 \%$ of the NBs were found to have hypoglycemia and $47.8 \%$ tio present neonatal jaundice.

With the increase of the survival of preterm newborns, there was a proportional rise of prevalence and severity of retinopathy of prematurity (ROP), which is one of the main causes of blindness that can be prevented at childhood. ${ }^{23}$ In the study, $16.6 \%$ of the NBELBs presented this morbidity, which can be related to the long term use of oxygen therapy, and which was diagnosed through evaluation of eye fundus examination.

The study showed that the most prevalent morbidities among NBELBs were the respiratory, cardiac, neurological and infectious ones. Even with modern technology available in care, the frequency of deaths was high for the population observed. The length of hospital stay in NICU was significantly increased by the presence of such morbidities as PDA, intraventricular hemorrhage and sepsis. The findings on the present study showed that the elevated rates of morbidity and mortality of NBELBs still persist as a great challenge in neonatal care.

de infecção hospitalar. ACTA Paul Enferm. 2007; 20 (1): 49-54.

4. BRASIL. Ministério da Saúde. Atenção ao pré-natal de baixo risco; 2012. 318 p.

5. Brasil. Ministério da Saúde. Atenção Humanizada ao Recém-Nascido de Baixo Peso: Metodo Canguru, Manual Técnico; 2011. 205 p.

6. Brasil. Atenção Humanizada ao Recém-Nascido de Baixo 
Peso: Método Mãe-Canguru: manual do curso. 2002. 282 p.

7. Neto JA de S, Rodrigues BMRD. Tecnologia como fundamento do cuidar em neonatologia. Texto Context Enferm. 2010; 19 (2): 372-7.

8. Lin HJ, Du LZ, Ma XL, Shi LP, Pan JH, Tong XM, Li QP, Zhou JG, Yi B, Liu L, Chen YB, Wei QF, Wu HQ, Li M, Liu CQ, Gao XR, Xia SW, Li WB, Yan CY, He L, Liang K, Zhou XY, Han SP, Lyu Q, Qiu YP, Li W, Chen DM, Lu HR, Liu XH, Liu H, Lin ZL, Liu L, Zhu JJ, Xiong H, Yue SJ, Zhuang SQ. Mortality and morbidity of extremely low birth weight infants in the mainland of china: a multi-center study. Chin Med J (Engl). 2015; 128 (20): 2743-50.

9. Cavallo MC, Gugistti A, Gerzeli S, Bsrbieri D, Zanini R. Cost of care and social consequences of very low birth weight infants without premature-related morbidites in Italy. Itl J Pediatr. 2015; 41(59): 1-12.

10. Wilson-Costello D, Friedman H, Minich N, Siner B, Taylor G, Schluchter M, Hack M. Improved neurodevelopmental outcomes for extremely low birth weight infants in 20002002. Pediatrics. 2007; 119 (1): 37-45.

11. Tommiska V, Heinonen K, Lehtonen L, Renlund M, Saarela T, Tammela O, Virtanen M, Fellman V. No improvement in outcome of nationwide extremely low birth weight infan populations between 1996-1997 and 1999-2000. Pediatrics. 2007; 119 (1): 29-36.

12. Gaiva MAM, Fujimori E, Sato APS. Mortalidade neonatal : análise das causas evitáveis. Rev Enferm UERJ. 2015; 23 (2): 247-53.

13. Costa R, Padilha MI. A unidade de terapia intensiva neonatal possibilitando novas práticas no cuidado ao recém-nascido. Rev Gaúcha Enferm. 2011;32(2):248-55

14. Brasil. Ministério da Saúde - DATASUS [internet]. Informações de Saúde. Acessado em 16/11/2015. Disponível em: http://tabnet.datasus.gov.br/cgi/tabcgi.exe? sinasc/cnv/nvse.def.
15. Lee YM, Cleary-Goldman J, D'Alton ME. Multiple gestations and late preterm (near-term) deliveries. Semin Perinatol. 2006; 30 (2): 103-12.

16. Silveira MF, Matijasevich A, Horta BL, Bettiol H, Barbieri MA, Silva AA, et al. Prevalência de nascimentos pré-termo por peso ao nascer: revisão sistemática. Rev Saúde Pública. 2013; 47 (5): 992-1003.

17. Gaiva MAM, Fujimori E. Mortalidade neonatal em crianças com baixo peso ao nascer. Ethiop J Heal Dev. 2010;24(1):87-8.

18. Tamez RN, Silva MJP. Enfermagem na UTI neonatal. 3 ed. Rio de Janeiro: Guanabara Koogan; 2006.

19. Dominguez GJ, Leboreiro JI, Macías MER, Zapata IB, Bahena EJP, Micha SA, García KLO, Palomino GT, Franco DD. Pesquisa o diagnóstico sintomático por ecocardiografía en la persistencia del conducto arterioso en prematuros. Rev Med Inst Mex Seguro Soc. 2015; 53 (2): 136-41.

20. Stoller JZ, DeMauro SB, Dagle JM, Reese J. Current Perspectives on Pathobiology of the Ductus Arteriosus. J Clin Exp Cardiolog. 2012; 8 (1): 1-29.

21. Lanzillotti LS, Seta MH, Andrade CLT, Junior WVM Eventos adversos e outros incidentes na unidade de terapia intensiva neonatal. Ciênc Saúde Coletiva. 2015; 20 (3): 937-46.

22. Bissinger RL, Annibale DJ. Thermoregulation in very lowbirth-weight infants during the golden hour: results and implications. Adv Neonatal Care. 2010; 10 (5): 230-8.

23. Graziano RM, Leone CR. Problemas oftalmológicos mais freqüentes e desenvolvimento visual do pré-termo extremo. J Pediatr (Rio J). 2005; 81 (1): 95-100.
Received on February 14, 2016

Final version presented on December 16, 2016

Approved on January 27, 2017 